\title{
La huella testimonial del refugio: usos y destinos del testimonio experto en las cortes de inmigración de Estados Unidos*
}

\begin{abstract}
NATALIA DE MARINIS
El objetivo de este artículo es analizar el papel y la circulación del testimonio experto en solicitudes de asilo en Estados Unidos. A partir de mi intervención como perito experto en cinco solicitudes de hombres indígenas mexicanos y del testimonio oral en una de ellas, reflexiono acerca de cómo las cortes se convierten en espacios de disputa ante la negación de la veracidad de la víctima, sustentada en procesos burocráticos y legales revictimizantes. Analizo el lugar del testimonio experto y tomo en cuenta las tensiones entre la objetividad pretendida y el involucramiento afectivo del etnógrafo, el lugar que ocupa en la creación de una huella testimonial ante la negación del refugio, y sus usos y destinos ante la criminalización de sujetos y grupos.
\end{abstract}

PALABRAS CLAVE: testimonio, testigo, peritaje, asilo, refugio

The Refugee Testimonial Path: Uses and Destination of Expert Witness Testimony at the Immigration Courts in the United States

This article seeks to analyze the role and the circulation of the expert testimony of the ethnographer in asylum cases in the United States. From my intervention as an expert witness in five requests involving Mexican indigenous men, and the oral defense in one of them, I will reflect on the way courts are becoming disputed spaces given attorney denial of the veracity of the victim. I argue that this negation is based on revictmizing bureaucratic and legal processes. I will analyze the role of the expert testimony in these processes, taking into account the tensions between the pretense of objectivity and the affective involvement of ethnography, the place testimony occupies in the construction of a testimonial trace that faces the negation of protection, and the uses and effects these testimonies have in the face of the criminalization of specific subjects and groups.

NATALIA DE MARINIS

Centro de Investigaciones y Estudios Superiores en Antropología Social-Golfo, KEYWORDS: testimony, witness, expert witness, asylum, refugee 


\section{Introducción}

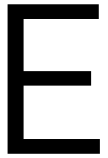

n Estados Unidos, los antropólogos comenzaron a formar parte de procesos judiciales como testigos en las cortes en la década de 1940, en casos que involucraban actores culturalmente diversos, en temas centrales del conocimiento antropológico que resultaban imprescindibles para la decisión de los jueces. Los casos implicaban problemas de segregación racial, leyes de mestizaje y comunidades religiosas, entre otros, y requerían el testimonio experto para informar sobre aspectos del contexto cultural y también para educar a los jueces en temas antropológicos (Stephen, 2018; Rosen, 1977; Campbell, Slack y Diedrich, 2017; Schmidt y Spector, 2018).

La idea del antropólogo como testigo ha supuesto, sin embargo, una reflexión más amplia en la trayectoria de la disciplina. Clifford Geertz (1989) acuñó la noción I-witnessing, yo-testifical, para definir y hacer una lectura crítica del valor que Malinowski (1973) dio a "estar allí”, que convertía al antropólogo en una autoridad de verdad. Aunque las nociones de verdad en los procesos judiciales no contemplan las mismas dimensiones que las ciencias sociales y las discusiones sobre la verdad abarcan un espectro muy amplio y complejo, las imbricaciones y relaciones mutuas se han expandido con más fuerza desde que los peritajes expertos se convirtieron en evidencia para las partes de los procesos jurídicos. En estos procedimientos, muchos antropólogos concuerdan en que los peritajes se centran en una estrategia para lograr argumentos "suficientemente buenos", lo que la mayoría de las veces implica abandonar la complejidad y la perspectiva deconstructiva del conocimiento antropológico (Campbell, Slack y Diedrich, 2017).

Este artículo se elaboró con el apoyo del proyecto "Primera fase de formación de un Laboratorio de Antropología Jurídica y Forense", del Centro de Investigaciones y Estudios Superiores en Antropología Social, coordinado por Rosalva Aída Hernández Castillo y Carolina Robledo Silvestre. 
En Latinoamérica, los peritajes antropológicos requeridos en los procesos judiciales fueron más tardíos. Al menos en México, comenzaron a solicitarse en casos que involucraban pueblos indígenas para la defensa de los derechos colectivos, a partir de la llamada era de reconocimiento de derechos colectivos, para educar a los jueces sobre las identidades étnicas, los usos del territorio, etc. (Valladares, 2012; Ortiz, 2018; Loperena, Hernández y Mora, 2018). En otros escenarios, por ejemplo, en los juicios por crímenes de lesa humanidad en Argentina, se ha recurrido a los "testigos de concepto/contexto" como voz experta de antropólogos e historiadores para coadyuvar en varias causas (Garaño, 2016). En los reportes expertos se busca información acerca del contexto de violencia del país de origen del solicitante y en casos específicos se rastrea información acerca del origen étnico de los solicitantes, si esto fuera un elemento central en la decisión final.

La pregunta acerca del testigo y el testimonio comprende un espectro de reflexiones en el que me gustaría ubicar el testimonio experto. En las últimas décadas, la escena jurídica se ha convertido en un espacio privilegiado de construcción de memoria, que a la vez colocó en el centro el testimonio de víctimas y testigos. Beatriz Sarlo (2006) reconoce la experiencia del Holocausto como el momento de proliferación del testimonio y la emergencia del sujeto, surgida en la ambigüedad en la que se sitúa el testimonio en el siglo XX. Sarlo analiza el ensayo "El narrador", de Walter Benjamin (2001), y concluye que si los soldados que volvían de la Primera Guerra Mundial enmudecidos representaban para Benjamin el fin de los relatos y de la conexión del sujeto y la experiencia, había ocurrido justamente lo contrario. El siglo XX sería el escenario del testimonio. En la Primera Guerra Mundial empiezan a registrarse, y durante y luego del Holocausto sumarían cientos de miles: nos enfrentamos a "masas de testimonios" (Wieviorka, 2006).
Sarlo (2006) afirma que la conmoción que experimentó Benjamin no fue por el fin del testimonio en sí, sino por la manera en la que la guerra aniquila la experiencia como un suceso comprensible. La guerra destruye la experiencia, que existe siempre que la víctima-sobreviviente sea capaz de narrarla y convertirse en testigo. El testimonio se amplía hacia otros, "el testigo se desdobla una y otra vez hasta, finalmente, incluirnos" (Gutiérrez, 2014: 36). Elizabeth Jelin (2002) llama a este desdoblamiento la huella testimonial, a partir de lo que Primo Levi (2005) planteó sobre la imposibilidad de narrar que habita en la víctima. La muerte de la víctima o la aniquilación de su condición humana convierte a los sobrevivientes — también víctimasen testigos, igual que a otros receptores de los testimonios, que hablan por delegación de aquellos a quienes se les ha arrebatado la capacidad de hacerlo (Levi, 2005: 480-481).

A partir de mi experiencia como testigo experta en cinco solicitudes de asilo de indígenas mexicanos en Estados Unidos ${ }^{1}$ y con base en la documentación de mi experiencia y elementos de autoetnografía, reflexionaré en este artículo acerca del testimonio como parte de ese desdoblamiento del testigo, producto de la intersección de varias causas que llevan a la imposibilidad de atestiguar que habita en las víctimas: por un lado, por la noción de "falso refugiado" que se instala como verdad ante la crisis de migración forzada en el mundo (Fassin, 2013); por el otro, por los espacios antropocéntricos y revictimizantes de justicia en los que se aniquila la veracidad de la víctima y los testigos, sobre todo de sujetos que históricamente han sido marginados de estos espacios, como las poblaciones indígenas (Stephen, 2017).

La participación de los testigos en las cortes ha sido poco explorada y me gustaría enfocarme en

Dos de los peritajes se elaboraron con la colaboración de Mariana Mora Bravo. 
este aspecto. Me centraré en las tensiones tanto del propio peritaje como en las creadas por los fiscales entre el valor del conocimiento profundo de un lugar y su deslegitimación en los escenarios performativos de la justicia por el involucramiento afectivo y la cercanía de la antropología; en la participación de los expertos en la huella testimonial ante la incertidumbre legal de los refugiados, y en los usos y efectos que la huella testimonial tiene en los procesos revictimizantes y de criminalización de determinados sujetos y grupos.

\section{El caso de Carlos en la corte de inmigración de San Francisco}

La abogada y dos asistentes del despacho pasaron por mí para ir a la corte de inmigración de San Francisco, donde se llevaría a cabo la primera audiencia del caso de Carlos, indígena mexicano de 23 años de edad, que hacía más de siete meses se encontraba en un centro de detención con amenazas de deportación por una falta administrativa: manejar alcoholizado mientras regresaba del panteón. ${ }^{2}$ Carlos había cruzado la frontera de manera irregular por primera vez junto a su padre, en 2003, a los nueve años. Dos años después fueron deportados. En 2009 volvió a cruzar y fue deportado en 2011. Se refugió en Sonora e ingresó de nuevo en diciembre de ese año. Como muchos indígenas mexicanos, se dedicaba a recolectar fresas. En su declaración ante los oficiales de inmigración en el centro de detención, Carlos presentó los motivos de su huida hacia Estados Unidos luego del asesinato de su padre:

Él [su padre] siempre luchó por la igualdad de la gente y tenía un compromiso muy grande con la comunidad. Había gente que no estaba de acuerdo con sus ideas y contrataron a un grupo de otra comunidad vecina para asesinarlo. [Un día] estando en una tienda de conveniencia pública de gobierno [...] dos hombres le dispararon y él murió. Tenía sólo 15 años y fui amenazado de muerte porque tenían miedo de que creciera y quisiera vengar la muerte de mi padre. Por mi propia seguridad, mi madre me apoyó para venir a Estados Unidos. Vine con una de mis hermanas y un año después me siguió mi mamá [...]. Toda mi familia tuvo que escapar de México, porque toda la familia estaba en peligro [...]. Si regreso a México seguramente seré asesinado. Soy el hijo mayor de mi familia y en nuestra cultura soy responsable por mi familia, por lo tanto, sería el principal objetivo para los asesinos de mi padre (declaración de Carlos, San Francisco, diciembre de 2016). ${ }^{3}$

La abogada me solicitó un reporte experto sobre la situación del pueblo y la región. Sin tener mucha información acerca de los procesos judiciales que involucran las solicitudes de refugio, llegué a San Francisco para dar mi testimonio en la corte. Los familiares de Carlos - madre, pareja, una hermana, el cuñado y tres niños pequeños, dos de ellos hijos de Carlos, ciudadanos estadounidenses - aguardaban en una sala de espera en uno de los pisos de la corte. Su madre no hablaba español, así que su hija fungió como intérprete. La abogada me señaló y dijo: "ella es quien va a ayudar a que Carlos salga. Es la única que puede explicarle a la jueza el miedo que tienen”. Luego de esa presentación, que me dejó casi sin aliento, y en la situación tensa que se vivía, con un oficial mirándonos, la madre tomó mis manos y me pidió que por favor los ayudara. La abogada intentaba comunicarse con el centro de detención, porque ese día Carlos también debía atestiguar. Aunque nunca supe si era parte de una estrategia,

\footnotetext{
2 Debido a que los casos están en proceso, se omitirá cualquier referencia contextual, histórica y documental que permita su reconocimiento.

3 Las traducciones son mías.
} 
no lograron comunicarse con él. El juicio se retrasaría, pero yo sí daría el testimonio.

Mientras esperábamos ingresar a la sala de audiencia, la mamá de Carlos se desplomó, cayó de rodillas al suelo llorando sin consuelo. Nos pidió que la ayudáramos, dijo que si deportaban a Carlos, todos se irían con él, y si volvían a México, los matarían. La situación era tan desesperante que la familia prefería enterarse y conocer el proceso, aunque todos pudieran ser deportados por no tener documentos. De hecho, a la salida de las cortes se registra un número importante de detenciones. ${ }^{4}$

La jueza, una mujer muy joven, se hizo presente. A excepción de la abogada defensora y el fiscal, los demás ocupábamos las sillas del público. Luego de mencionar algunos puntos específicos del expediente, me invitaron a sentarme a la derecha del estrado de la jueza. Tenía un pequeño micrófono y una caja con pañuelos desechables. Los familiares se retiraron a petición del fiscal. Los otros dos abogados del despacho de la parte defensora se quedaron entre el público y fueron apoyos centrales para mí.

La abogada me hizo preguntas relacionadas con mis credenciales, intentó dejar en claro toda mi experiencia en el tema. A continuación, el fiscal me hizo preguntas durante tres horas. Al salir de la audiencia, y mientras intentaba recordar y recuperar lo acontecido, reconocí tres momentos del interrogatorio que se me presentaban como círculos. El primero era una pregunta de opinión general para llegar al caso de Carlos y desarticular la lógica de mis argumentos, sobre todo por la empatía que pudiera mostrar. Esto quedó claro desde el comienzo, cuando no preguntó por mis credenciales, sino por mi experiencia migratoria y la de mi padre, que quizá dedujo por mi apellido y mi trayectoria migratoria. Buscaba asentar la posibilidad de que una persona migrante defendiera a otra en la misma condición.

Si bien desarticular a los testigos es parte de la performance jurídica, la manera en que se agudiza en el contexto de políticas conservadoras y regresivas en la garantía de derechos a migrantes en Estados Unidos y el mundo es un aspecto central que me permite encuadrar lo que experimenté en ese interrogatorio. El estrés al que son sometidos los migrantes, sus abogados y los testigos es tal que me han pedido más de siete reportes expertos urgentes desde que hice el de Carlos: "le admito que cada caso es más difícil bajo este presidente Trump", comentó un abogado por correo electrónico en la última solicitud que recibí. En otros recorridos en el edificio de la corte de inmigración para otro caso el mismo año, me impactó ver la cantidad de salas nuevas para audiencias que se habían construido en un solo piso.

\section{La negación de las condiciones del refugio}

Carlos solicitó asilo luego de haber sido detenido por manejar alcoholizado en el estado de California, una falta administrativa que podría significar seis años de cárcel, o en su caso, la deportación. De inmediato contactó a una abogada de inmigración, quien al entrevistarlo reconoció que podía ser

$4 \quad$ Esta práctica se hizo más común con el comienzo de la administración de Donald Trump. Sin embargo, en enero de 2018 se elaboró una misiva para la detención de inmigrantes dentro de las cortes estatales y locales cuando acuden a sus citas. El Servicio de Inmigración y Control de Aduanas de Estados Unidos (ICE, por sus siglas en inglés) plantea en la misiva que estas acciones se justifican por la falta de voluntad de parte de los oficiales de los tribunales locales y estatales para arrestar "extranjeros específicos con condenas penales, miembros de pandillas, amenazas a la seguridad nacional o seguridad pública, extranjeros que han sido expulsados de los Estados Unidos pero que no han salido y extranjeros que han regresado, que ingresaron de manera ilegal al país después de ser retirados, cuando los oficiales o agentes del ICE tienen información que los llevan a creer que los extranjeros objetivo están presentes en ese lugar específico" (USICE, 2018). La traducción es mía. 
sujeto de protección como refugiado. En Estados Unidos hay varios tipos de protección que implican ciertas características para la solicitud y derivan en condiciones determinadas para permanecer en el país. El asilo se otorga cuando la persona demuestra que en su país de origen vive persecución y su vida corre peligro por motivos de raza, religión, nacionalidad, o por pertenecer a un grupo social o político específico. ${ }^{5} \mathrm{El}$ asilo se solicita un año después de ingresar al país y el solicitante necesita demostrar 10\% de riesgo de ser asesinado en caso de ser deportado. ${ }^{6}$ Esta protección permite obtener la ciudadanía para el sujeto asilado y su familia - esposo o esposa e hijos-.

Una segunda figura es el aplazamiento de expulsión —withholding of removal-, que difiere del asilo en dos cuestiones centrales: puede solicitarse aun con antecedentes de deportación o más años de residir en el país sin documentos, pero requiere demostrar más de 51\% de probabilidades de riesgo en caso de ser deportado. Con esta figura sólo el sujeto protegido obtiene la residencia con permiso de trabajo en Estados Unidos.

Como señalaron algunos abogados, se recurre a esta segunda solicitud de protección cuando el sujeto no califica para el asilo. En el caso de migrantes mexicanos, casi siempre se debe a deportaciones previas o a que llevan más de un año en Estados Unidos sin haber solicitado protección. Una tercera figura se sustenta en las causas contenidas en la Convención contra la Tortura (CAT, por sus siglas en inglés) que requiere demostrar el riego de sufrir tortura en caso de ser retornado a su país. ${ }^{7}$

El procedimiento para probar algunas de estas causas se apoya en el proceso legal adjudicatorio mediante audiencias, en las que el sujeto debe demostrar el miedo creíble y la evidencia de persecución pasada o futura en su país de origen en caso de ser deportado. Si bien la ley de inmigración no define persecución, históricamente se vinculó a la que es perpetrada por gobiernos, que en la actualidad se extiende a grupos no gubernamentales, como guerrillas, grupos paramilitares, etc. En este último caso, se requiere demostrar que el gobierno es incapaz de controlarlos. En los procesos judiciales, que pueden durar años, los solicitantes presentan evidencia testimonial subjetiva y evidencia objetiva, en ocasiones por un testigo experto. Los casos se resuelven uno por uno, pero sus sentencias pueden sentar precedentes que amplían las causas y los sujetos de protección y ayudan a otros en la misma situación.

El caso de Carlos, por ejemplo, era importante porque la demostración de persecución por ser hijo de un líder abriría las puertas a otros casos en situaciones similares. Según la abogada, por esta razón no se resolvería sólo en una audiencia y sería necesario apelar a una instancia mayor. Mientras el proceso está en marcha, el sujeto no puede ser deportado. Para muchos, embarcarse en estos procedimientos lentos, y a veces muy costosos, es la única alternativa para permanecer en Estados Unidos.

Según Kelcey Baker y colaboradores (2018), los casos que apuntan a un grupo social específico son los más difíciles de ganar porque no hay una definición exacta que determine la pertenencia. El grupo social específico se describe como personas que comparten características inmutables, que pueden ser innatas, como sexo, color o lazos de parentesco. Pueden incorporarse experiencias pasadas comunes, como la formación militar o la tenencia de tierras, entre otras.

$6 \quad$ Existen dos solicitudes posibles: el asilo afirmativo, para personas que no están sujetas a expulsión - se solicita un año después de haber ingresado a Estados Unidos-, y el asilo defensivo, para personas que sí están sujetas a expulsión.

7 El estándar para probar la tortura es muy alto comparado con la demostración de persecución en las dos protecciones anteriores. Es necesario demostrar que la tortura proviene de las fuerzas públicas del país o de otros grupos bajo el conocimiento y la complicidad del gobierno. La protección de la CAT, que sólo impide el retorno al país de origen, no exenta a quienes tienen antecedentes criminales, como sí ocurre con los solicitantes de asilo y el aplazamiento de expulsión. 


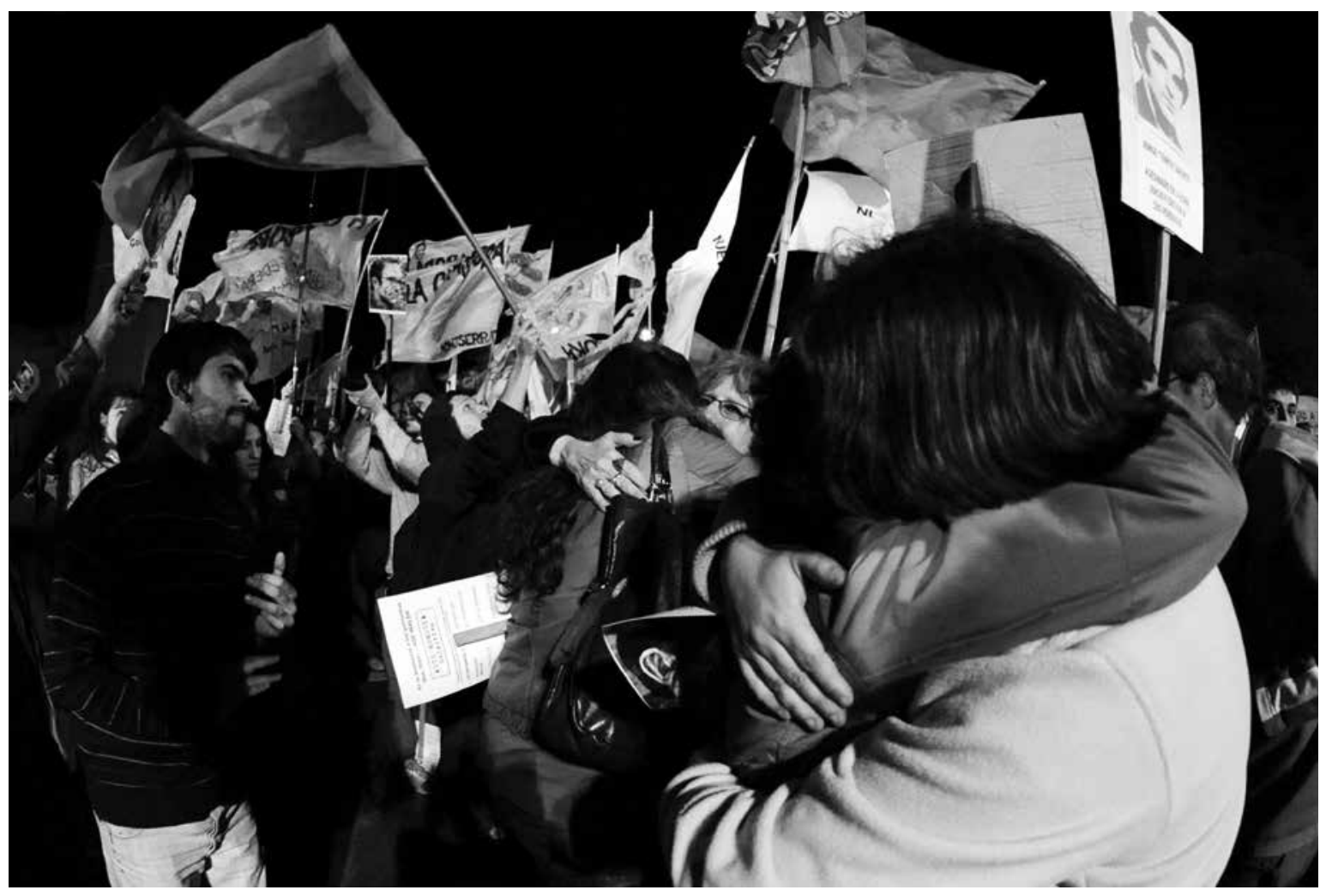

RICARDO RAMíREZ ARRIOLA $/ 360^{\circ}$ - A las afueras de los Tribunales Comodoro Py, la gente espera la sentencia del juicio a 18 represores de la dictadura cívicomilitar argentina. Buenos Aires, 26 de octubre de 2011.

La solicitud de Carlos es una entre las 63823 que presentaron ciudadanos mexicanos en los últimos años, de las cuales sólo se garantizó el asilo para 464 (Schmidt y Spector, 2018). Aunque muchos fueron denegados, la mayoría se encuentra en pausas que pueden durar años. Samuel Schmidt y Carlos Spector (2018) plantean que los números varían mucho según la fuente. El United States Department of Justice (USDJ) afirma que en 2016 se recibieron 12831 solicitudes de asilo de mexicanos, de las cuales 2624 fueron negadas y 2615 obtuvieron el aplazamiento de expulsión. Otros están en proceso o han tenido otras resoluciones. La diferencia numérica según las fuentes llama la atención. Para Schmidt y Spector (2018), esto se debe a la necesidad de negar la situación de restricción de protección cada vez mayor que los migrantes enfrentan bajo la presidencia de Donald Trump. Como confirman otros trabajos, en 2016 se negó cerca de $90 \%$ de los casos de apelación de asilo de mexicanos (Campbell, Slack y Diedrich, 2017: 329).

Desde la Convención de Ginebra del 28 de julio de 1951, precedida por la creación del Alto Comisionado de las Naciones Unidas para los Refugiados (ACNUR), la condición histórica de asilo se volvió objeto de regulación en muchos países. En Estados Unidos, a partir del Protocolo de Nueva York, en 1967, se consideró que la protección podría ser un estatus igualitario para todas las personas. Sin embargo, a medida que el número total de refugiados del mundo creció, la protección y el asilo han disminuido: 530000 personas fueron protegidas en Estados 
Unidos luego de la Segunda Guerra Mundial y sólo 275000 en 2010, aunque el número de refugiados haya crecido seis veces en ese lapso (Fassin, 2013). Amnistía Internacional reportó en 1990 que los casos que evidenciaban una violación al espíritu de la Ley de Asilo en Estados Unidos eran las solicitudes denegadas de refugiados de El Salvador, Guatemala y Haití, países en los que se estaban cometiendo violaciones graves a los derechos humanos. Entre 1983 y 1989, sólo 39 de 1834 haitianos solicitantes fueron protegidos, en contraste con $72.6 \%$ de asilos garantizados para personas provenientes de la Unión Soviética, seguidos por 70.3\% de aceptados de Rumania y $61.5 \%$ de Irán. En el mismo periodo, sólo se garantizó el asilo a 1.3\% de las solicitudes presentadas por guatemaltecos y $2 \%$ de refugiados salvadoreños (citado en Anker, 1990: 81).

El aumento de solicitantes de refugio ${ }^{8}$ ha llevado a suponer que buena parte no son refugiados sino que emigraron por motivos económicos (Castles, 2003). Sin embargo, es difícil diferenciar los motivos de la movilidad porque la violencia provoca otros efectos devastadores que obligan a las personas a huir, como crisis económicas y de infraestructura social. Aunque las categorías restrictivas acerca del riesgo físico que una persona pueda demostrar no se relacionan con la complejidad del fenómeno, que encubre otras dimensiones, es importante reconocer que la categoría de refugiado se ha convertido en objeto de suspicacias y ha llevado a que las personas enfrenten prácticas cada vez más inquisitivas acerca de su pasado y su futuro posible. La enorme burocratización de estos procesos en el Norte global tiene como consecuencia años de incertidumbre y especulación, que derivan en procesos traumáticos e inciertos, en los que las personas se enfrentan a una condición en extremo vulnerable.

El miedo a ser deportado se relaciona también con lo que Tanya Golash-Boza (2016) sugiere sobre la interrelación generizada y racializada entre la crecida industria carcelaria y las deportaciones masivas.
De los deportados, 97\% son hombres latinos. Durante la administración de Barack Obama se registró el mayor número de deportaciones, con dos millones. Las reformas a las políticas de inmigración desde mediados de la década de 1990 hicieron posible la ampliación de causales, la disminución de las órdenes para frenarla y el aumento de presupuesto. ${ }^{9}$ El Servicio de Inmigración y Control de Aduanas de Estados Unidos (ICE, por sus siglas en inglés) no sólo tiene objetivos de deportación por cumplir —400000 anuales desde 2010 - , también la llamada "Immigration Detention Bed Quota”, aprobada por el Congreso en 2009, garantiza fondos para mantener 34000 camas ocupadas al día en los sistemas privados de detención de inmigrantes, quienes esperan su deportación o la atención de oficiales de inmigración (Sinha, 2017). ${ }^{10}$ Las elevadas ganancias de esta modalidad se combinan con las que genera el sistema carcelario. Ambas formas de represión estatal se aplican sobre todo a los cuerpos de hombres negros y latinos.

8 Según las estadísticas del USDJ, entre 2012 y 2016 se presentaron 468534 solicitudes de asilo. En 2012, del total de 48321, 11331 fueron de mexicanos, de las cuales se garantizaron sólo 117. Siguen 10720 solicitudes de ciudadanos de China, de las cuales se garantizó cerca de 50\%. El Salvador ocupó el tercer lugar, con 3554 solicitudes, de las que se garantizaron sólo 156. De las 3413 solicitudes de Guatemala, se garantizaron 192. De la India, hubo 1884 solicitudes y se aprobaron 250. En sexto lugar están los 1552 solicitantes de Honduras, de los que se garantizaron 73. En 2016, los primeros cuatro países fueron México y los países del Triángulo Norte de Centroamérica. México mantuvo un número similar al de 2012, con 12831 solicitudes, y ocupó el segundo lugar luego de El Salvador, con 17709 solicitudes. Siguieron Guatemala, con 11354, y Honduras, con 10 812. El porcentaje de garantía varía entre 3 y 6\% (USDJ, 2017).

9 En 1996 se aprobaron dos leyes que transformaron las políticas migratorias, Illegal Inmigration Reform and Immigrant Responsability Act (IIRA) y Anti-Terrorism and Effective Death Penaltiy Act (AEDPA).

10 También se ha recibido información acerca de los trabajos forzados en las cárceles privadas de inmigrantes, que están proliferando en el país. Véase Burnett (2017). 


\section{El testimonio del experto en la construcción de la huella testimonial}

La creación de procesos cada vez más sofisticados para definir quién es un refugiado se basa en la desconfianza en la veracidad del refugiado para reducir de manera significativa el grupo de los "refugiados verdaderos", "una tarea probablemente más difícil de lo que uno imagina, ya que la mayor parte de la evidencia — desde los hechos relatados hasta los documentos presentados - puede ser impugnada" (Fassin, 2013: 53). La noción de falso refugiado, que genera una mayor presión y burocratización de los procesos, implica una lucha mayor para abogados defensores y organizaciones de migrantes, a la que se integran académicos mediante reportes expertos.

Con las reformas migratorias de la década de 1990, la política migratoria estadounidense elevó la burocratización de las solicitudes de asilo. En 1991 se incluyó la entrevista del miedo creíble para obtener información sobre los motivos para solicitar asilo. La persona, entrevistada por un oficial de inmigración, aporta detalles del contexto, el reclamo específico y los daños pasados y futuros, que incluyen la posibilidad de sufrir agravios en cualquier parte del país o de ser asilado por otro país que no sea Estados Unidos. A esto le sigue una serie de audiencias en la que se presentan las pruebas del miedo.

El reporte experto es uno de los testimonios que se integran. Aunque es central en la resolución, se convierte también en objeto de cuestionamiento. Como plantea Lynn Stephen (2017), quien ha acompañado numerosos casos de solicitud de asilo, el peritaje y el testimonio oral en las cortes es una herramienta fundamental para proporcionar elementos contextuales y culturales específicos como evidencia de la persecución del solicitante. El conocimiento experto implica no sólo aportar datos importantes del contexto, sino, idealmente, un conocimiento profundo del lugar de procedencia del solicitante.
El testimonio experto se utiliza para proporcionar evidencia objetiva de la solicitud de refugio y se presenta en la audiencia, en formato escrito y oral, y de manera presencial o telefónica, cuando el sujeto tiene una orden de deportación en su contra, ya sea presencial o telefónica. Los jueces determinan la admisibilidad de una persona como experta con base en la relevancia, las certificaciones y la confianza. ${ }^{11}$

Si bien el trabajo de los testigos expertos está cobrando una importancia radical en estos procedimientos legales, Lawrence Rosen (1977) hace un recorrido por los usos que se le ha dado al conocimiento antropológico en las cortes de Estados Unidos desde la década de 1940. De todos los casos en los que se recurrió al conocimiento antropológico, en el que hubo mayor necesidad de antropólogos expertos y definió su emergencia para una diversidad de casos fue el de la Ley de Comisiones de Reclamaciones Indias, de 1946. El testimonio tuvo como fin probar la demanda territorial, lo que generó que este involucramiento en los procedimientos haya "servido no sólo para educar a muchos antropólogos en la naturaleza del testimonio experto, sino también para educar a las cortes y a los abogados en el uso y relevancia del conocimiento antropológico" (Rosen, 1977: 567).

El auge del uso del conocimiento antropológico como evidencia es más reciente en Latinoamérica. Sobre todo a raíz de los reconocimientos multiculturales y la llamada judicialización de la política, la demanda del saber experto se fortaleció, principalmente "con el objetivo de determinar la validez de las demandas culturales que fundamentan los reclamos por derechos colectivos" (Loperena,

Aunque de manera menos estricta, se utilizan las características de la Federal Rules of Evidence para aceptar a los expertos, basadas en "la relevancia de la evidencia, la eficiencia en introducirla, la confiabilidad de la evidencia y la honestidad general en todo el proceso de juicio adversarial" (Baker et al., 2018: 44). 
Hernández y Mora, 2018: 9). Sin embargo, muchos autores han argumentado de manera crítica que el reconocimiento de los derechos colectivos ha puesto a este conocimiento en una posición hegemónica, que reifica relaciones de subordinación de los derechos y saberes de los colectivos porque afianza el conocimiento occidental del experto como el único capaz de determinar la validez de ciertos aspectos de la cultura (Valladares, 2012; Ortiz, 2018). Por último, los procesos legales en los que se insertan los peritajes no sólo legitiman un tipo de conocimiento sobre la cultura indígena por encima de los sujetos indígenas, también tienen efectos racializantes y de género en el escenario y los discursos jurídicos.

En los peritajes que hice tanto para el caso de Carlos como para otros, me enfrenté a varias de estas cuestiones. En todos fue necesario delimitar un grupo étnico específico, elemento clave para fundamentar la persecución por formar parte de un grupo social y solicitar refugio. Como se trataba de población indígena, describir el territorio compartido y la lengua era central; sin embargo, en la corte, el fiscal solicitó que detallara la raza del solicitante, lo que no pude hacer, aunque puse énfasis en el racismo, que entendí como el objetivo de su pregunta.

Un segundo punto crítico de los peritajes fue demostrar la persecución que había experimentado Carlos después del asesinato de su padre, en 2007, que había detonado un riesgo para toda la familia y en especial para él por ser el hijo mayor. Para evidenciar el miedo, fue necesario contextualizar la situación de violencia que atraviesa la región de origen y explicar que rebasa los límites de los estados en los que se asienta la población con la misma pertenencia étnica. También fue preciso hablar de las organizaciones políticas y el control de las comunidades, así como de la estructura patrilineal de herencia de la tierra y organización local para pormenorizar el peligro que vive el hijo varón mayor en caso de quedarse en la región y que se sospeche de su "posible deseo de vengar la muerte de su padre", como Carlos refirió en la entrevista del miedo creíble. En este caso, la tensión aumentó porque declaró pertenecer a una organización a la que luego acusó de perseguirlo. Aunque sólo los líderes ejerzan un poder negativo para la gente y no haya opción de participar o no, haber dicho que formaba parte de ella dejaba a Carlos en una situación más difícil, en la que tuve que poner especial cuidado en la elaboración del reporte y en la que me detendré en el punto siguiente.

El involucramiento que supone para los antropólogos defender solicitudes de refugio tiene implicaciones para los registros y en la manera en la que se esencializan ciertos elementos de la cultura, que si bien pueden ser positivos para la resolución de un caso, pueden tener efectos negativos para otros, sobre todo por la construcción de visiones estáticas que pueden criminalizar a ciertos grupos, regiones o países. Para los antropólogos Howard Campbell, Jeremy Slack y Brian Diedrich, que han participado con testimonios expertos en más de 100 casos de solicitudes de asilo, los académicos deberían presentar argumentos "suficientemente buenos", que dejen “de lado el típico tratamiento deconstructivo de los antropólogos para reificar los tropos culturales, o incluso las propias concepciones del inmigrante, y redirigirlos en el contexto legal" (2017: 332).

Si bien plantean la necesidad de un posicionamiento pragmático y urgente, es indispensable atender los efectos negativos de esta urgencia más allá del ámbito legal o para la resolución de otros casos. La manipulación de serpientes, la ingestión de peyote o cuestiones que criminalizan prácticas culturales específicas fueron defendidas en cortes por los expertos ante la urgencia de salvar al sujeto, que en el caso de los solicitantes de refugio puede implicar la culpabilización de ciertos usos y costumbres violatorios de sus derechos individuales, como la dote, los aportes monetarios a las organizaciones políticas o la autonomía indígena, que hace que las organizaciones indígenas se perciban como 
“incontrolables". Algunas de estas aseveraciones, planteadas por varios antropólogos como problemas significativos en la elaboración de peritajes, pueden tener consecuencias negativas porque convierten al sujeto en alguien socialmente incapacitado, debido a factores culturales que no le permiten tener prácticas sociales aceptables.

Hay un acuerdo acerca de que el uso esencialista de ciertos rasgos culturales es un arma de doble filo en muchos casos, sobre todo por la tensión entre los derechos individuales y colectivos. Muchas veces se preserva una mirada individual por encima de las afectaciones colectivas, porque solo una persona solicita asilo - en la representación de lo mexicano, cierta cultura indígena, el machismo, etc.—; esta situación puede afectar los casos siguientes porque dejan un antecedente no favorable (Stephen, 2017; Campbell, Slack y Diedrich, 2017).

Sumado a las dificultades de la orientación legal del conocimiento antropológico, en los sistemas de justicia oral el testimonio enfrenta otros retos, como las estrategias de desestructuración de los fiscales para quebrar los argumentos de los testigos, que suponen también impactos emocionales que provocan descontrol en las afirmaciones. Se han documentado quejas de los peritos expertos acerca de las preguntas que reciben, que tienden a distorsionar o tergiversar el testimonio y la verdad de lo plasmado en el reporte escrito (Rosen, 1977: 572). Además de las dificultades propias de estos escenarios, en los que víctimas y testigos enfrentan presiones y un ambiente estresante, mi experiencia en las solicitudes de asilo me lleva a plantear que también el experto es considerado un "falso potencial". Por ello, mi intención en el próximo punto es doble. Por un lado, me interesa mostrar los efectos de la circulación del testimonio experto al ser leído desde una perspectiva que criminaliza a determinados sujetos, y por el otro, quiero exponer la manera en que, aun en estas circunstancias, el testimonio experto se torna clave para la creación de una huella testimonial que permita crear un registro tanto dentro como fuera del espacio jurídico, una huella del refugio que visibilice una realidad negada por políticas migratorias cada vez más restrictivas.

\section{Los dilemas y posibilidades del testimonio experto}

El testigo experto se encuentra en la misma ambigüedad que el asilo contemporáneo. Como argumenta Didier Fassin (2013), si la verdad del asilo implica un derecho sagrado de protección en un espacio inviolable, el asilo contemporáneo se enfrenta siempre al riesgo de hostilidad. Detrás de estas ambigüedades está la negación de la verdad del solicitante y los testigos, y la desconfianza acerca de los motivos de la migración. Las restricciones que planteé para otorgar protección se agudizan cada vez más con la criminalización que encaran los sujetos que cruzan las fronteras y la intención de declarar países de tránsito, como México, como seguros. En Estados Unidos, mientras se difundía el escándalo de la separación de niños de sus padres en la frontera, ${ }^{12}$ se hacían públicas las pretensiones de declarar a México como un país seguro, lo que podría derivar en una restricción de las solicitudes no sólo de mexicanos, sino también de centroamericanos que cruzan por México, por haber pasado por un país

12 La política de cero tolerancia que la administración de Trump declaró en abril de 2018 establecía que todos los migrantes que cruzaran la frontera de manera irregular, aun cuando pidieran asilo en Estados Unidos, se convertían en objeto de persecución criminal. Así, casi 2000 niños fueron separados de sus padres durante un periodo de seis semanas, entre abril y mayo, porque no podían permanecer en cárceles federales. Las imágenes y videos de niños en jaulas que pedían entre lágrimas ver a sus padres produjeron una gran conmoción y la condena nacional e internacional. 
seguro antes de llegar a Estados Unidos (Semple, 2018; Campbell, Slack y Diedrich, 2017).

Algunos autores vinculados al acompañamiento legal y de documentación etnográfica sostienen que la mayoría de las negaciones de asilo se fundamentan en el reconocimiento de la efectividad de las acciones de seguridad que México implementa (Schmidt y Spector, 2018; Querales, 2017). En una de las sentencias, por ejemplo, se citó la detención de Joaquín El Chapo Guzmán para rechazar una solicitud de asilo (Schmidt y Spector, 2018: 103). En otros casos, el asilo se niega para no admitir la participación de policías municipales en actividades criminales; muchas veces se presentan argumentos absurdos, como en el caso de Efraín, documentado por May-ek Querales Mendoza (2017), en el que una jueza afirmó que la vinculación entre policías y el crimen organizado era imposible y que México protege a sus ciudadanos con compensaciones y becas para los hijos.

Los peritajes enfrentan estos escenarios de hostilidad que buscan negar las circunstancias por las que las personas solicitan protección, sobre todo porque la resolución de los casos sienta precedentes tanto para la negación como para la protección en casos similares. La solicitud de Carlos era estratégica porque podía dejar un antecedente para otros hombres del mismo pueblo. Como dijo la abogada, podía "abrir la llave" para que este grupo indígena se convirtiera en un social group sujeto a asilo directo, por las características de la guerra en la que viven y el refugio masivo en Estados Unidos.

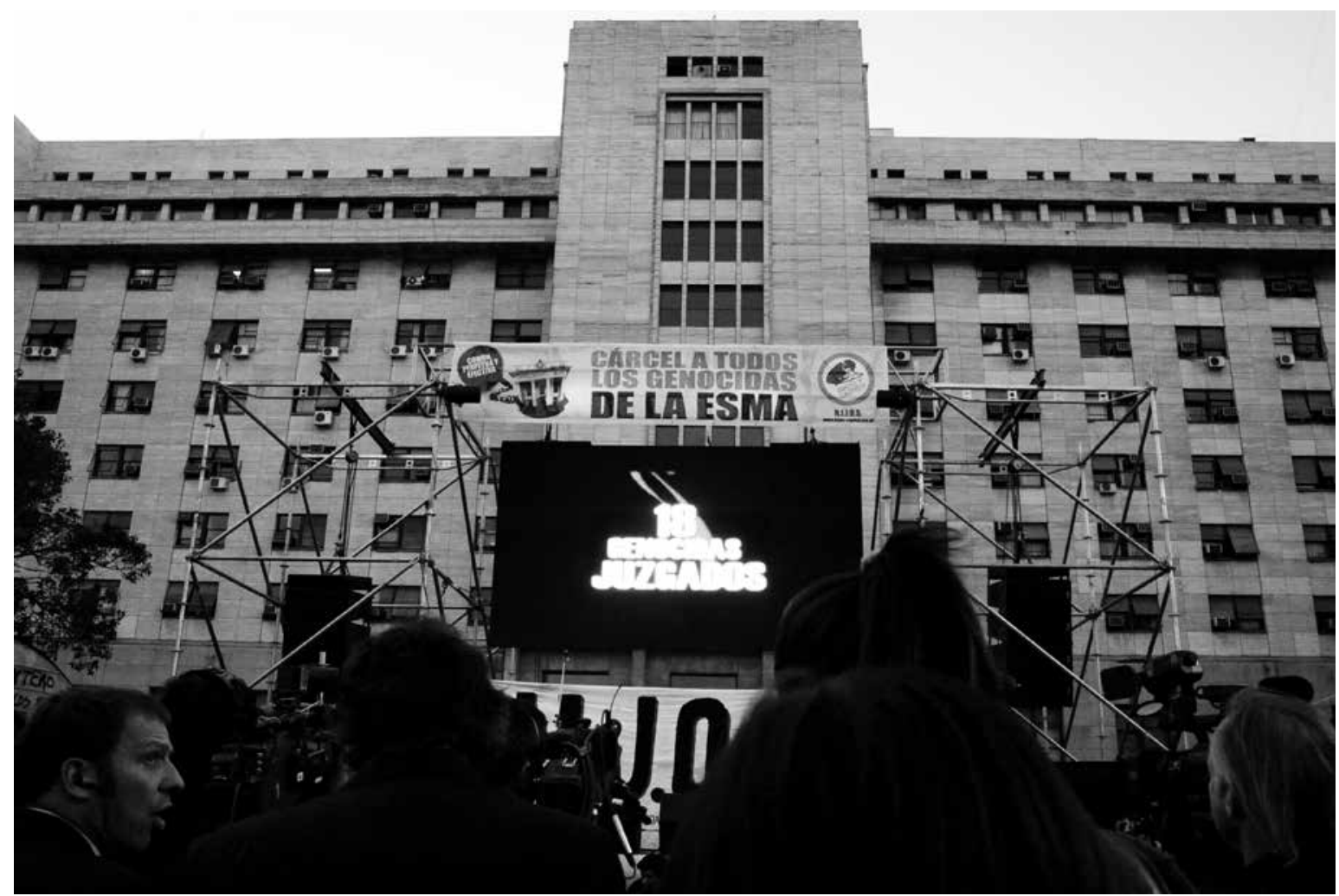

RicARdo RamíreZ ARRIOLA $/ 360^{\circ}$ - En el segundo juicio de la Megacausa de la Escuela de Mecánica de la Armada, 16 de 18 represores fueron encontrados culpables de 86 crímenes de lesa humanidad y condenados a penas de entre 18 años y prisión perpetua. Buenos Aires, Argentina, 26 de octubre de 2011. 
El eje del peritaje acerca de las condiciones por las cuales Carlos emigró fue el asesinato de su padre en el contexto de las movilizaciones indígenas en México desde la década de 1990, que continuaron hasta principios del siglo XXI. El asesinato de su padre era un punto fundamental que conectaba y explicaba el miedo real del solicitante, y el fiscal se enfocó en él durante el interrogatorio. Una nota periodística del diario La Jornada, que utilicé como evidencia, vinculaba los sucesos: durante las elecciones de 2007, varios líderes de comunidades se negaron a instalar casillas electorales, lo que desató algunos asesinatos selectivos, entre ellos, el del padre de Carlos.

El fiscal me preguntó si en el peritaje constaba que lo habían asesinado por rehusarse a instalar casillas electorales. Dije que sí. Luego de una sucesión de preguntas cortas para confirmar datos clave en el peritaje, preguntó si había citado la nota periodística. Dije que sí. Me preguntó por el título y respondí que no lo recordaba con exactitud, pero que informaba acerca de una situación política en la que algunas personas habían sido asesinadas en relación con el surgimiento de disidencias de las organizaciones políticas históricas en la región, en el contexto de movilizaciones indígenas. El fiscal cuestionó el uso de ese periódico y no otros, y preguntó por la parte de la nota que mencionaba que el padre de Carlos había sido asesinado por rehusarse a instalar casillas electorales. Le dije que no recordaba dónde lo decía. Hizo muchas preguntas más sobre la nota con el propósito de forzarme a afirmar cosas de las que en ese momento comenzaba a dudar. Luego del hostigamiento, dio copias de la nota a todos los presentes y me pidió que leyera el título.

El título hablaba del contexto de emergencia de un conflicto en la región debido a que varias comunidades se habían negado a instalar casillas electorales. El párrafo que mencionaba la muerte del padre de Carlos no hacía referencia al acto de rehusarse a instalar casillas que planteaba el título, sino que aparecía como un dato menor, marginal y desvinculado del título de la nota. Aunque ésa no era la prueba contundente para afirmarlo, sino mi conocimiento de esa época, sentí una frustración enorme y una duda respecto a lo que había defendido en el peritaje. Expliqué que al leer una nota se tiene en cuenta todo el contenido, y lo que relacionaba todos los eventos eran mis entrevistas con otros líderes. Buena parte de mi trabajo versaba sobre la situación que atravesaban muchos líderes indígenas y comunidades cuando se negaban a seguir instrucciones de los partidos políticos.

Hice un esfuerzo enorme por recordar mis encuentros con el líder del que aprendí tanto, pero sentía miedo de ser engañada por mis propios recuerdos. Me sentía quebrada emocionalmente. Empecé a recordar que muchas personas que había conocido habían sido asesinadas. Me recordé ahí, en la guerra y la desesperación. No pude hablar más y pedí una pausa. En un tono que simulaba cierta empatía, el fiscal me dijo "se nota la pasión que tienes por este pueblo". La pausa fue usada a su favor. Para mí era claro que mis años de trabajo de campo en esa región me dotaban de un conocimiento que pocos tenían, pero para el fiscal eso me convertía no sólo en un testigo de contexto y hechos, sino también en una persona con vínculos emocionales que podría descalificar la pretensión de objetividad que se busca en los expertos.

El otro punto problemático fue que, en la entrevista del miedo creíble, Carlos dijo ser miembro de la organización acusada de estos asesinatos. Esto me llevó a plantear en el peritaje el contexto complejo en el que desenvolvió la persecución de Carlos y el que se vive en esa región en particular, en la que formar parte de organizaciones políticas no es una opción. El objeto de mi peritaje fue la manera en la que se organizan comunidades y colectivos específicos, y traté de defenderlo en la audiencia. El fiscal evitó el tema y trató de encasillar su cuestionamiento en víctimas y victimarios, para forzarme 
a describir ciertas organizaciones como criminales para sostener el razonamiento de que si Carlos había formado parte de una de ellas, él también era un criminal.

Fue evidente que este fiscal pretendía definir organizaciones criminales para restringir solicitudes futuras y criminalizar a otros migrantes. Después confirmé con otros abogados que estos procedimientos dejan huella para clasificar grupos terroristas.

El dilema principal de los peritajes es que la defensa de un caso puede marcar un grupo social particular como sujeto de asilo político directo o como sujeto de persecución por formar parte de un grupo terrorista. Este planteamiento toma en cuenta otros aspectos, como cuestiones de género, pues los peritajes pueden usarse para deslegitimar solicitudes de hombres de determinados grupos étnicos por criminalizar ciertas prácticas culturales (Stephen, 2017). Así como el reporte experto puede sentar antecedentes para garantizar derechos de protección, la defensa de una víctima individual puede tener repercusiones negativas para otros del mismo grupo.

\section{Reflexiones finales}

Hay una función historiadora en los escenarios de justicia, por la contribución a la verdad y la transmisión de la experiencia, y una posibilidad para la víctima de construir una narrativa que contrarreste los efectos desarticuladores de la guerra; sin embargo, como se ha analizado en los juicios por crímenes de lesa humanidad en Latinoamérica, ni la verdad ni estos escenarios son unívocos, sino que representan lugares de disputa (Vechiolli, 2012). Si bien las condiciones individuales en los casos de asilo no representan la dimensión colectiva de la violencia política de grandes masacres, las solicitudes muestran la articulación y acumulación de agravios, y cómo la violencia política y estructural se inscribe en las historias individuales. La performance escrita y oral del testimonio experto requiere la construcción de un marco interpretativo "que una la historia individual y sus peticiones de asilo en un lugar, tiempo y una serie de circunstancias particulares que iluminen y refuercen los reclamos del demandante" (Stephen, 2018: 104). A pesar de que las sentencias son la clave de los antecedentes judiciales, la mayoría de las veces se apelan en instancias mayores y los testimonios se convierten en archivo y memorias fundamentales.

Carlos salió del centro de detención después de la audiencia y su proceso para el asilo aún continúa. En la foto que me mandó la abogada, noté la felicidad que invadía a la familia, que también me contagió. Ella comentó por correo electrónico que pagó una fianza para esperar el proceso de solicitud gracias al efecto de mi peritaje, que había dado "mayor seriedad al proceso". Carlos es uno de los tantos migrantes que están en la intersección creciente de criminalizaciones que se vive en Estados Unidos ante el sistema de detención y deportación que busca ganancias a partir de la represión y el miedo. Las cortes se han transformado en arenas de disputa para abogados, solicitantes y testigos que luchan contra las políticas y los discursos racistas y antiinmigrantes, agravados por la política de cero tolerancia de la administración de Donald Trump. Los peritajes se insertan como apoyos individuales en estos procesos, y pese a todos los cuestionamientos a los que pueden estar sometidos, logran dar peso a las voces de las víctimas en la estructura jerárquica y racializada de los espacios de justicia. En alguna oportunidad, en la audiencia de Carlos, la abogada hizo referencia a la necesidad de imaginar las condiciones de los testimonios de las víctimas si yo había sido objeto de ese cuestionamiento.

Los testimonios que quedan en los archivos de las audiencias se convierten en huellas testimoniales de la violencia que se vive en México, negada por el gobierno de Estados Unidos. Estas trayectorias de violencia de larga duración, como muestra el 
proceso que vivió el padre de Carlos, son objeto de enormes sospechas, sobre todo cuando admitir ciertas persecuciones y dejar esos antecedentes en el ámbito legal puede detonar el reconocimiento de guerras silenciadas y favorecer otros otorgamientos de asilo. En las cortes se dirimen los destinos de las solicitudes y por eso son espacios de disputa tan importantes. Sin embargo, el reto de los peritajes, sobre todo para mexicanos y centroamericanos, se presenta cuando las categorías raciales e ideológicas en esta invisibilización se convierten en argumentos explícitos o implícitos, no sólo para negar el asilo, sino para perpetuar la criminalización y persecución de otros en las mismas condiciones. $\mathbb{D}$

\section{Bibliografía}

Anker, Deborah, 1990, “U.S. Immigration and Asylum Policy: A Brief Historical Perspective”, en International Migration Review, vol. 13, pp. 74-85. Baker, Kelcey, Katherine Freeman, Gigi Warner y Deborah Weissman, 2018, Expert Witnesses in U.S. Asylum Cases: A Handbook, University of North Carolina Chapel Hill-School of Law, Chapel Hill. Disponible en línea: <http://www.law.unc.edu/documents/academics/humanrights/ expertwitnesshandbook.pdf>

Benjamin, Walter, 2001, “El narrador”, en Walter Benjamin, Para una crítica de la violencia. I/uminaciones IV, Taurus, Madrid, pp. 111-134.

Burnett, John, 2017, “Big Money as Private Immigrant Jails Boom”, en NPR, 21 de noviembre. Disponible en línea: <https://www.npr.org/2017/11/21/ 565318778/big-money-as-private-immigrant-jails-boom>.

Campbell, Howard, Jeremy Slack y Brian Diedrich, 2017, "Mexican Immigrants, Anthropology, and United States Law: Pragmatics, Dilemmas, and Ethics of Expert Witness Testimony”, en Human Organization, vol. 76, núm. 4, pp. 326-335.

Castles, Stephen, 2003, "The International Politics of Forced Migration”, en Socialist Register, vol. 39, núm. 1, pp. $172-192$.

Fassin, Didier, 2013, "The Precarious Truth of Asylum”, en Public Culture, vol. 25, núm. 1, pp. 39-63.

Garaño, Santiago, 2016, “La experiencia del 'testigo de concepto/contexto' en el juicio Operativo Independencia”, en La Escuelita de Famaillá, 24 de noviembre. Disponible en línea: <http://escuelitadefamailla.org/la-experiencia-del-testigo-de-conceptocontexto-en-el-juiciooperativo-independencia-i/>.

Geertz, Clifford, 1989, El antropólogo como autor, Paidós, Barcelona.

Golash-Boza, Tanya, 2016, "The Parallels between Mass Incarceration and Mass Deportation: An Intersectional Analysis of State Repression", en Journal of World-Systems Research, vol. 22, núm. 2, pp. 484-509.

Gutiérrez, Carlos, 2014, "La mirada y la voz del testigo", en Carlos Gutiérrez y Gervasio Noailles (comps.), Destinos del testimonio: víctima, autor, silencio, Letra Viva, Buenos Aires, pp. 13-26.

Heyman, Josiah y Jeremy Slack, 2018, "Bloakading Asylum Seekers at Ports of Entry at the US-Mexico Border Puts Them at Increased Risk of Eploitation, Violence, and Death", en Center for Migration Studies of New York, 25 de junio. Disponible en línea: <http://cmsny.org/ publications/heyman-slack-asylum-poe/>.

Jelin, Elizabeth, 2002, Los trabajos de la memoria, Siglo XXI Editores, Madrid.

Levi, Primo, 2005 [1986], "Los hundidos y los salvados”, en Primo Levi, Trilogía de Auschwitz, Océano, Madrid.

Loperena, Christopher, Rosalva Aída Hernández Castillo y Mariana Mora, 2018, "Los retos del peritaje cultural. El antropólogo como perito en la defensa de los derechos indígenas", en Desacatos, núm. 57, pp. 8-19.

Malinowski, Bronislaw, 1973, Los argonautas del Pacifico occidental: un estudio sobre comercio y aventura entre los indígenas de los archipiélagos de la Nueva Guinea melanésica, Península, Barcelona

Malkki, Liisa, 1995, Purity and Exile: Violence, Memory and National Cosmology among Hutu Refugees in Tanzania, The University of Chicago Press, Chicago.

Ortiz Elizondo, Héctor, 2018, “De fronteras disciplinarias: diálogos entre la antropología y la criminología”, en Desacatos, núm. 57, pp. 20-35. Querales Mendoza, May-ek, 2017, “'La corte negará la solicitud presentada’: peticiones mexicanas de asilo político en Estados Unidos y su interpretación cultural en la corte migratoria en el contexto de la guerra contra el narcotráfico", en Abya Yala. Revista sobre Acesso á Justiça e Direitos nas Américas, vol. 1, núm. 3, 154-176.

Rosen, Lawrence, 1977, "The Anthropologist as Expert Witness”, en American Anthropologist, vol. 79, núm. 3, pp. 555-578. 
Sarlo, Beatriz, 2006, Tiempo pasado. Cultura de la memoria y giro subjetivo. Una discusión, Siglo XXI Editores, México.

Schmidt, Samuel y Carlos Spector, 2018, "Asilo político de mexicanos en Estados Unidos. Causas y respuesta”, en Cambios y Permanencias, vol. 9, núm. 1, pp. 100-142.

Semple, Kirk, 2018, "U.S. Pushes Plan to Make Mexico Handle Asylum Seekers", en The New York Times, 17 de mayo. Disponible en línea: <https://www.nytimes.com/2018/05/17/world/americas/mexico-migrants-caravan-asylum.html>

Sinha, Anita, 2017, "Arbitrary Detention? The Immigration Detention Bed Quota”, en Duke Journal of Constitutional Law and Public Policy, vol. 12, núm. 2, pp. 77-121.

Stephen, Lynn, 2017, “Bearing Witness: Testimony in Latin American Anthropology and Related Fields", en The Journal of Latin American and Caribbean Anthropology, vol. 22, núm. 1, pp. 85-109.

__ , 2018, "Gendered Violence and Indigenous Mexican Asylum Seekers: Expert Witnessing as Ethnographic Engagement”, en Anthropological Quaterly, vol. 91, núm. 1, pp. 325-362.

United States Department of Justice (USDJ), 2017, "Asylum Statistics FY 2012-2016". Disponible en línea: <https://www.justice.gov/eoir/file/ asylum-statistics/download>.

United State Immigration and Custom Enforcement (USICE), 2018, "Directive Number 11072.1: Civil Immigration Enforcement Actions at Courthouses Directive", 19 de enero. Disponible en línea: <https://www.ice.gov/sites/default/files/documents/Document/2018/ciEn forcementActionsCourthouses.pdf>.

Valladares, Laura, 2012, "La importancia del peritaje cultural: avances, retos y acciones del Colegio de Etnólogos y Antropólogos Sociales, A. C. (CEAS) para la certificación de peritos”, en Boletín del Colegio de Etnólogos y Antropólogos Sociales, año 2012, pp. 11-20.

Vecchioli, Virginia, 2012, "Derechos humanos y violencia política en la Argentina. Disputas en torno a la memoria del pasado reciente”, en A Contracorriente, vol. 10, núm. 1, pp. 249-279.

Wieviorka, Annette, 2006, The Era of The Witness, Cornell University Press, Ithaca. 